\title{
The Workings of Simurgh Metaphor in Distributed Leadership
}

\author{
Alireza Hejazi \\ School of Business \& Leadership, Regent University, Virginia Beach, USA \\ Email: alirhej@regent.edu
}

Received 6 April 2014; revised 16 May 2014; accepted 26 June 2014

Copyright (C) 2014 by author and OALib.

This work is licensed under the Creative Commons Attribution International License (CC BY). http://creativecommons.org/licenses/by/4.0/

(c) $\underset{\mathrm{EY}}{\mathbf{B}}$ Open Access

\begin{abstract}
This article offers an organizational metaphor based on an Iranian epic Manteq-o-Teyr or The Logic of Flight. The metaphor is shaped by the story of a wise hoopoe bird whose dream was to reach a mountain called Qaf and find the great king of birds called Simurgh or Thirty Birds. The new enlightenment resonated with the Conference of the Birds, captures the idea of why and how leader and followers should connect their consciousness to each other to achieve a higher level of wisdom, mythically called Simurgh. The story communicates a metaphor that works in favor of explaining organizational components such as design, structure, environment, and boundaries in a distributed style of leadership as practiced by the hoopoe and his follower birds as a community of practice through collective wisdom.
\end{abstract}

\section{Keywords}

Collective Wisdom, Communities of Practice, Distributed Leadership, Metaphor, Simurgh

Subject Areas: Education, Literature, Management Organization, Philosophy, Sociology

\section{Introduction}

Boal and Hooijberg [1] argue that the essence of strategic leadership involves the capacity to learn, the capacity to change, and managerial wisdom. According to McKenna et al., "strategic leadership requires wisdom to provide excellence in judgment, insight and character and that if the principle features of wisdom are understood leaders can be evaluated according to a robust criteria based on these principles.” ([2] p. 177).

Wisdom goes beyond individual level of a leader's mental functioning and embraces all the team members' intellectual capabilities. Organizational leaders can draw on the collective wisdom of others' experience and compassionately walk with organizations through their transformation [3]. Leadership is not a one-way road cruised only by the leader, but traveled together with the led. This echoes distributed leadership a concept that bears many similarities to notions such as "shared", "collective", "collaborative", "emergent" and "co-" leader- 
ship and has some common theoretical and practical origins [4].

An effective tool of applying wisdom in leadership is metaphor. Metaphors use analogies to express complex ideas simply, and so they clarify the ambiguity and uncertainty that characterize work. Organizational metaphors may come from the military ("Let's nuke 'em”"), football ("It's fourth and ten”), medicine ("We need a tourniquet, not a band-aid"), horticulture ("It's time for heavy pruning”), engineering ("That group can't carry its weight"), and so forth [5]. Metaphors have an important impact on organizational culture because they influence the way in which employees perceive the organization and their own roles within it.

The application of metaphors in organizational leadership is aimed at providing a better understanding of leadership functions and organizational issues. Metaphors help the individual to develop a method of concept ualization where items with different characteristics are compared to show similarities and not differences. Metaphors and analogies are especially effective when they excite the imagination and engage the listener in trying to make sense out of them [6]. In an organizational context metaphors are used to describe structure and framework of operations. For example, organizations have been likened unto how machines function, analyzed from an organismic perspective and according to the function of the brain [7].

The most famous parable describing the role of wisdom in leadership in Persian culture is composed by the twelfth-century Iranian perfumer and alchemist, Farid ad-Din Attar (c. 1146-1220) who was also a Sufi poet. In his masterpiece The Conference of the Birds, he tells the story of the birds gathered around the hoopoe (a mythical bird), who was chosen by lot toguide them on a journey to see the Simurgh: King of the Birds. The metaphor of Simurgh captures the idea of why and how leader and followers should connect their consciousness to each other so that they can achieve a higher level of wisdom in The Thirty Birds, mythically called Simurgh, much like the mythical Phoenix in the Western culture.

This article uses the metaphor of Simurgh to explain organizational components such as design, structure, environment, and boundaries in a distributed style of leadership as practiced by the hoopoe and his follower birds as a community of practice through collective wisdom. Based on previous research on culture it is observed that culture impacts leadership style as well as organizational development [8]. The metaphor of Simurgh deduces the story of The Conference of the Birds to a new culture so that leaders and followers may prefer following it as an effective model of distributed leadership to achieve greater efficiency by mobilizing collective engagement and challenging or reinforcing traditional forms of organization [4].

\section{What Is the Metaphor of Simurgh?}

Attar's epic "Manteq-o-Teyr" or "The Logic of Flight" reflects a metaphor where a hoopoe bird as a leader whose vision was to reach a mountain called "Qaf " takes the leadership of thousands of birds as a community of practice and finds The King of Birds in the character of "Simurgh" or "Thirty Birds" who reached down the road successfully. The metaphor of Simurgh is chosen here as it serves the distributed model of leadership. Organizational metaphors have been used for various purposes including attempts to rationalize and synthesize theories which derive from very different origins, areas of interest and methods of inquiry [9].

Retold by Aslan ([10], pp. 206-208), to reach the Simurgh, the birds would have to traverse seven treacherous valleys, each representing a station along the way. The first step was taken towards the Valley of the Quest, where the birds should reject the world and repent of their sins. That was followed by the Valley of Love, where the birds would jump into the seas of fire to enflame their very being. The next level was the Valley of Mystery, where the birds should take a different way that could be fit for their pilgrimage. In the Valley of Detachment, all the birds had to lose their claims, selfishness, and even lust for meaning. Coming into the Valley of Unity, they were merged into one being, resembling the concept of oneness in diversity. By the sixth station, the Valley of Bewilderment, the birds broke through the veil of traditional dualities and suddenly confronted with the emptiness of their being. Down the road, the birds arrived at the Valley of Nothingness, where they stripped of their egos and were consumed by the spirit of the universe. By passing all those seven valleys the birds learned to deny the mountain of the Self and give up the intellect for love, so they were allowed to continue to the throne of the Simurgh.

Only ninety nine birds out of thousands of birds could manage ending the journey with the hoopoe. These thirty birds were led to the presence of the Simurgh. Yet when they finally set their eyes upon him, they were surprised to see not the King of Birds, but themselves. In Persian language Simurgh is a symbol of those thirty birds who resemble the concept of oneness in diversity. 
This enlightenment resonates with the concept of collective wisdom and can serve as a metaphor to the better understanding of distributed leadership at communities of practice. The functioning and elements of the metaphor are introduced in the following sections through an organizational perspective. The elements of this metaphor are listed in the following table (Table 1) according to their organizational role.

The social impact of using metaphors at organizational level cannot be neglected. Social constructionism poses the idea that we construct our social world and our knowledge of that world in our everyday interactions [11]. The proposition of Simurgh metaphor in this article is aimed at facilitating those interactions by applying collective wisdom in leadership function and designing an informal structure of organization.

\section{How Does Simurgh Metaphor Work?}

According to Morgan [7], all theories of organization and management are based on implicit images or metaphors that lead us to see, understand, and manage organizations in distinctive yet partial ways. The metaphor of Simurgh communicates an image that: 1) sees organization by visioning as a community of practice, 2) understands it by collective wisdom, and 3) manages it by an informal structure through distributed leadership. The functioning of this metaphor at organizational level is depicted in Figure 1.

Taking a narrative approach to culture demands more than just collecting and analyzing the content of stories-it involves engaging with storytelling. The cultural significance of stories lies as much in the teller's expressive artistry and the listeners' responses, as it does in the content of the story told, as American folklorist Michael Owen Jones once reminded [11].

The hoopoe's desire for reaching "Qaf” mountain and finding the King of Birds "Simurgh" reflects his vision building. The hoopoe communicates that vision to other birds like a professional leader and convinces them to form a group that can be interpreted as an organization and seek Simurgh together. The hoopoe uses not only his wisdom, but also the wisdom of other birds that had brilliant ideas. It is an echo of collective wisdom. They face many difficulties in their travels, and by the time they at last reach Qaf Mountain, only thirty birds remain alive. Those thirty birds took roles in their endeavor towards Qaf. They finally come to understand that "Simurgh" for whom they have endured all the hardships of travel is their own 30-member group-that they themselves are the real "Simurgh" or "30 Birds." That victory became possible through a distributed style of leadership that the hoopoe and all other ninety nine birds adapted by accepting their responsibilities as a community of practice.

Morgan [7] uses "metaphors" to explain the complex character of organizational life and notes that any theory or perspective that we bring to the study of organization and management, while capable of creating valuable insights, is also incomplete, biased and potentially misleading. Simurgh metaphor is not a perfect description of organizational design and structure, though it encourages the participation of all organization members in the process of leadership as far as they follow common vision, goals and values.

\section{What Are the Organizational Elements of Simurgh Metaphor?}

In Morgan's [7] view, the art of using metaphor is to find fresh ways of seeing, understanding, and shaping the situations that we want to organize and manage. The metaphor of Simurgh explains design, structure, environment, and boundaries of an organization in a distributed style of leadership in the communities of practice.

Table 1. The elements of Simurgh metaphor.
\begin{tabular}{cc}
\hline Metaphor Element & Organizational Role \\
\hline Hoopoe Bird & Leader \\
Conference of Birds & Organization \\
Reaching Qaf Mountain & Vision \\
Visiting Simurgh (The King of Birds) & Mission \\
"Simurgh” or “Thirty Birds” & Collective Wisdom/Community of Practice \\
Birds' Roles in Leadership & Distributed Leadership \\
Seven Valleys & Organizational Growth/Development \\
\hline
\end{tabular}




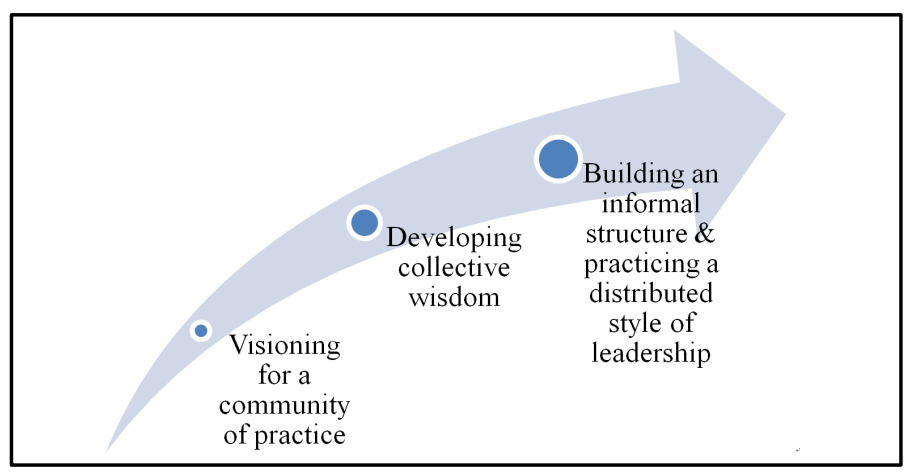

Figure 1. The functioning of Simurgh metaphor at organizational level.

\subsection{Design}

Simurgh metaphor encourages a bottom-up design for organization. It allows "higher" or more evolved forms of wisdom to emerge. The leader determines the organizational design by assessing the organization from the bottom up. It is based on the concept of communities of practice, informal relationships and distributed leadership.

Introduced by educational theorists Wenger and Lave, the concept of communities of practice initially offered an answer to the question of how learning occurs through social interaction [11]. Wenger and Lave defined a community of practice as "a group of people, informally bound together by common interests in learning and the development of knowledge, who share repertoires (e.g., routines and vocabularies). A community of practice, described as self-designing and self-managing, forms when a group of people collectively develop ideas, knowledge, and practices as they learn together” ([11], p. 116).

That explanation of the concept of communities of practice made by Hatch and Cunliffe [11], exactly describes the communities of birds who made a huge informal self-designed and self-managed group, mainly based on their common goal-finding their Great King. Finding Simurgh gave meaning to their travel passing through seven valleys.

The link between design and control has been considered since the early days of design research as documented in the writings of Archer [12]. Zamenopoulos and Alexiou's [13] study demonstrates that the peculiarity of design rests on the fact that the distinction between theories and models is an anticipated but emergent state. In contrast, control-based representations assume that the theory-model distinction is given in advance, as an intrinsic characteristic. They believe that design is a distinct paradigm in relation to control. In this sense, Simurgh metaphor prepares a design that is devoted to the shared control of leader and the led. It suggests an organizational design that enables self-organization.

The organizational design recommended by Simurgh metaphor also resonatesan organization suitable for practicing distributed leadership. In fact, it is an informal organization. In this design, enduring organizational structures (e.g. committees and teams) are put in place to facilitate collaboration between individuals [14]. Leadership is naturally assumed by members of group and shared organically between individuals [15]. In this design the purpose of the upper layers of the organization is to serve the purposes of the lower layers [16].

The desired design suggested by Simurgh metaphor establishes a good connection with modern day's findings. The results of De Toni et al.'s [17] study highlight important organizational design choices to enable self-organization process: organic structure composed by activity systems to enable reconfiguration; roles enlargement and enrichment and cognitive diversity to enable redundancy; collaboration and participatory decision-making and social capital and networking to enable interconnection; values adaptation, motivations and rules to enable sharing principle. All these merits can be found in the proposed organizational design of Simurgh metaphor.

\subsection{Structure}

Simurgh metaphor brings a proper structure for distributed leadership to the organization. Shared or distributed leadership occurs when all members of a team are fully engaged in the leadership of the team and are not hesitant to influence and guide their fellow team members in an effort to maximize the potential of the team as a whole [18]. Itcould be defined as an emergent team property that results from the distribution of leadership influence across multiple team members. 
Specifically, Simurgh metaphor provides a dynamic, interactive structure where individuals in groups are entitled to a leadership that is broadly distributed among a set of individuals instead of centralized in the hands of a single individual who acts in the role of as uperior [19]. According to Yukl [6], the most extreme form of distributed leadership occurs when there is no authority hierarchy, all important decisions are made collectively, and all leadership responsibilities are shared among the members. Teams with this much autonomy are most likely to be found in small employee-owned businesses, cooperatives, communes, and social clubs.

In Hatch and Cunliffe's [11] view, because individuals belong to many different communities of practice, each having their own ways of talking that produce a context for local meaning making and identity construction, an organization's social structure can embrace multiple communities of practice, each emerging spontaneously in response to particular interests, needs, desires, or problems. Appelo [20] takes distributed control as a component of self-organization. In his view, distributed control is crucial for the survival of complex systems.

From the symbolic perspective, the accumulation of distributed organizational identity/image/brand/reputation components, and the arc of their ever-changing trajectory, produces the social construction Hatch and Cunliffe [11] call OUP (referring to their publisher at Oxford University Press). Those who study communities of practice similarly argue for a culturally contextualized appreciation of the phenomenon of practice. They tend to focus attention on discourses framinga shared knowledge base that canbe applied through practice to solving practical organizational problems. Attar's skillful use of seven valleys in the story of Simurgh frames a shared knowledge base referring to seven phases that should be completed before getting a reliable form of collective wisdom.

\subsection{Environment and Boundaries}

In the metaphor of Simurgh, the travel of birds under the shared leadership of a wise hoopoe starts with a high degree of uncertainty, but at the same time is highlighted with hope. In fact, the community of those traveling birds can be labeled by external uncertainty and internal learning.

The response of the birds as a group to external uncertainty can be interpreted in terms of isomorphism. It means that the organization takes on the same form as its environment [11]. The survival and prosperity of an organization depends on effective adaptation to the environment [6]. In this sense, an essential leadership function is to help the organization adapt to its environment and acquire resources needed to survive. The wise hoopoe of Simurgh story did this perfectly by offering proper advice to the birds during their expedition.

The internal learning provided by Simurgh metaphor can be understood within the framework of learning organizations. The hoopoe bird develops a community where individual and group development is an essential element of achieving goal (visiting Simurgh). The building and transfer of knowledge is widely discussed in the story with respect to "explicit knowledge" as described by Hatch and Cunliffe ([11], p. 304), and the internal environment is fully proper for the learning of all members (birds).

Taking the Conference of Birds even as a complex adaptive system, one may see that extensive interaction, learning by doing, and experiment that are fundamental parts of the natural adaptive process for organizations are provided by this metaphor [21]. Drawing on the apparent similarities in those processes, Simurgh metaphor describes self-organizing activities and the emergence of new systems as a model for a new type of learning environment.

The vibrant pluralistic environment surrounding the traveling birds became a breeding ground for sharing ideas and exciting leadership experimentation, the most important of which was self-confidence. The self-constructional structure of Simurgh metaphor can make a balance between power and leadership and reconciles the individual dynamics of trait theories of leadership and the environmental positions of situational theories of leadership. The final output would be a self-organized organization.

According to Hatch and Cunliffe [11], communities of practice can cross boundaries drawn between businessunits and project teams, hierarchies, or any other dimension of social structure. Individuals can move between different communities, sharing and brokering knowledge as they do so. Like networks, communities of practice are characterized by connections rather than hierarchicalor formalized relationships, making the manager's role one of enabling organizational learning and innovation.

\section{Conclusion}

Any narrative depends upon the perspective and location of its author. Coming from Sufism ideology and the 
Iranian cuture, the twelfth-century Iranian perfumer and alchemist, Farid ad-Din Attar (c. 1146-1220) suggests the concept of collective wisdom in his masterpiece The Conference of the Birds. The hoopoe's role as the leader of birds who was chosen to guide them on a journey to see the Simurgh (the King of the Birds) communicates a strong metaphor in which the leader and followers are encouraged to connect their consciousness to each other so that they can achieve a higher level of wisdom. This article uses the metaphor of Simurgh to explain organizational components such as design, structure, environment, and boundaries in distributed model of leadership as practiced by the hoopoe and his follower through collective wisdom.

Normally, a symbolic perspective like Simurgh metaphor encourages managers to understand how communities of practice emerge from the problems and interests that employees take responsibility for, rather than proposing issues around which they would like to see communities of practice form and then setting expectations for their formation [11].

In this metaphor, hoopoe bird functions as the leader, the Conference of Birds is taken as organization, reaching Qaf Mountain is the vision, visiting Simurgh (the King of Birds) is the mission, "Simurgh" or "Thirty Birds" reminds collective wisdom practiced in a community, the birds' roles in a participative leadership resonates distributed leadership, and Seven Valleys are symbols of organizational growth and development. The metaphor of Simurgh communicates an image that sees organization by visioning as a community of practice, understands it by collective wisdom, and manages it by an informal structure through distributed leadership.

Simurgh metaphor encourages a bottom-up design for organization. It allows "higher" or more evolved forms of wisdom to emerge. The leader determines the organizational design by assessing the organization from the bottom up. It is based on the concept of communities of practice, informal relationships and distributed leadership. It provides a dynamic, interactive structure where individuals in groups are entitled to a leadership that is broadly distributed among a set of individuals instead of centralized in the hands of a single individual who acts in the role of a superior. The self-constructional structure of Simurgh metaphor can make a balance between power and leadership and reconciles the individual dynamics of trait theories of leadership and the environmental positions of situational theories of leadership. The final output would be a self-organized organization.

The metaphor of Simurgh deduces an Iranian epic to a new culture so that leaders and followers may prefer following it as an effective model of distributed leadership to achieve greater efficiency by mobilizing collective engagement and challenging or reinforcing traditional forms of organization.

\section{References}

[1] Boal, K.B. and Hooijberg, R. (2001) Strategic Leadership Research: Moving on. Leadership Quarterly, 11, 515-549. http://dx.doi.org/10.1016/S1048-9843(00)00057-6

[2] McKenna, B., Rooney, D. and Boal, K. (2009) Wisdom Principles as a Meta-Theoretical Basis for Evaluating Leadership. The Leadership Quarterly, 20, 177-190. http://dx.doi.org/10.1016/j.leaqua.2009.01.013

[3] Benefiel, M. (2005) The Second Half of the Journey: Spiritual Leadership for Organizational Transformation. The Leadership Quarterly, 16, 723-747. http://dx.doi.org/10.1016/j.leaqua.2005.07.005

[4] Bolden, R. (2011) Distributed Leadership in Organizations: A Review of Theory and Research. International Journal of Management Reviews, 13, 251-269. http://dx.doi.org/10.1111/j.1468-2370.2011.00306.x

[5] Beazley, H., Boenisch, J. and Harden, D. (2002) Continuity Management: Preserving Corporate Knowledge and Productivity When Employees Leave. John Wiley \& Sons, Hoboken.

[6] Yukl, G.A. (2013) Leadership in Organizations. 8th Edition, Prentice-Hall, Upper Saddle River.

[7] Morgan, G. (2006) Images of Organization. Sage, Thousand Oaks.

[8] Dorfman, P., Javidan, M., Hanges, P., Dastmalchian, A. and House, R. (2012) GLOBE: A Twenty Year Journey into the Intriguing World of Culture and Leadership. Journal of World Business, 47, 504-518. http://dx.doi.org/10.1016/j.jwb.2012.01.004

[9] Royer, S. (2006) Strategic Management and Online Selling: Creating Competitive Advantage with Intangible Web Goods. Routledge, New York.

[10] Aslan, R. (2006) No God but God: The Origins, Evolution, and Future of Islam. Arrow Books.

[11] Hatch, M.J. and Cunliffe, A.L. (2013) Organization Theory: Modern, Symbolic, and Postmodern Perspectives. 3rd Edition, Oxford University Press, New York.

[12] Archer, B.L. (1970) An Overview of the Structure of the Design Process. In: Moore, G.T., Ed., Emerging Methods in Environmental Design and Planning, MIT Press, Cambridge, 285-307. 
[13] Zamenopoulos, T. and Alexiou, K. (2007) Rethinking the Cybernetic Basis of Design: The Concepts of Control and Organization. Kybernetes, 36, 1570-1589. http://dx.doi.org/10.1108/03684920710827607

[14] Gronn, P. (2010) Hybrid Configurations of Leadership. In: Bryman, A., Collinson, D., Grint, K., Jackson, B. and Uhl-Bien, M., Eds., Sage Handbook of Leadership, Sage, London, 435-452.

[15] MacBeath, J., Oduro, G.K.T. and Waterhouse, J. (2004) Distributed Leadership in Action: A Study of Current Practice in Schools. National College for School Leadership, Nottingham.

[16] Meadows, D.H. (2008) Thinking in Systems: A Primer. Chelsea Green, White River Junction.

[17] De Toni, A.F., Biotto, G. and Battistella, C. (2012) Organizational Design Drivers to Enable Emergent Creativity in Web-Based Communities. The Learning Organization, 19, 335-349. http://dx.doi.org/10.1108/09696471211226699

[18] Pearce, C.L. (2004) The Future of Leadership: Combining Vertical and Shared Leadership to Transform Knowledge Work. Academy of Management Executive, 18, 47-57. http://dx.doi.org/10.5465/AME.2004.12690298

[19] Pearce, C.L. and Conger, J.A. (2003) Shared Leadership: Reframing the Hows and Whys of Leadership. Sage, Thousand Oaks.

[20] Appelo, J. (2011) Management 3.0: Leading Agile Developers, Developing Agile Leaders. Pearson Education, Boston, MA.

[21] Englehardt, C.S. and Simmons, P.R. (2002) Creating an Organizational Space for Learning. The Learning Organization, 9, 39-47. http://dx.doi.org/10.1108/09696470210414818 